\title{
Beneficiaries of conflict: a qualitative study of people's trust in the private health care system in Mogadishu, Somalia
}

This article was published in the following Dove Press journal:

Risk Management and Healthcare Policy

I August 2017

Number of times this article has been viewed

\author{
Abdi A Gele ${ }^{1-3}$ \\ Mohamed Yusuf Ahmed ${ }^{4}$ \\ Prabhjot Kour ${ }^{2}$ \\ Sadiyo Ali Moallim ${ }^{5}$ \\ Abdulwahab Moallim Salad ${ }^{3}$ \\ Bernadette Kumar ${ }^{2}$ \\ 'Institute of Nursing and Health \\ Promotion, Department of Health, \\ Oslo and Akershus University College \\ of Applied Science, ${ }^{2}$ Department \\ for Research, Norwegian Centre \\ for Minority Health Research, \\ Oslo, Norway; ${ }^{3}$ Center for Health \\ Research, Somali National University, \\ ${ }^{4}$ Department of Business Management, \\ Simad University, ${ }^{5}$ Faculty of Medicine, \\ Benadir University, Mogadishu, \\ Somalia
}

Background: In 2005, the World Health Conference called for all nations to move toward universal health coverage, which is defined as "access to adequate health care for all at an affordable price". Despite this, an estimated $90 \%$ of Somalia's largely impoverished population use private health care. Therefore, considering that the private health care system is the dominant health care system in Mogadishu, Somalia, exploring the accessibility to, as well as people's trust in, the private sector is essential to help contribute an equitable and affordable health care system in the country.

Methods: A qualitative study using unstructured interviews was conducted in Mogadishu from August to November of 2016. A purposive sampling approach was used to recruit 23 participants, including seven medical doctors who own private health centers, eight patients, five medical students and three senior officials who work for the Ministry of Health. Data were analyzed using a thematic analysis.

Results: Our findings show that the private health care system in Mogadishu is not only unregulated but also expensive, with the cost of health care often unaffordable for the majority of the country's citizens. There is evidence of prescription of inappropriate treatment, tendency to conduct unnecessary laboratory tests, excessive use of higher diagnostic technologies and overcharging - including the widespread practice of further appointments for follow-up - which inflates the costs. The study also found poor patient-provider relationship and widespread distrust of the private health care system.

Conclusion: The study findings underline the need for the Somali government to develop regulatory mechanisms and guidelines with the potential to guide the private health care sector to provide equitable and affordable health care to people in Mogadishu. The doctor-patient relationship has been - and remains - a keystone of care; thus, there is an urgent need for guidelines for private health care providers to treat their patients with dignity and respect. The education system, particularly the syllabus used by medical faculties, should be reviewed and improved to provide medical students with necessary knowledge, skills and attitudes to maintain patient dignity and rights.

Keywords: Somalia, private health care, user fees, dignified care

\section{Background}

Correspondence: Abdi A Gele Institute of Nursing and Health Promotion, Department of Health, Oslo and Akershus University College of Applied Science, Pilestredet 32, Oslo 0167, Norway

Tel +4796822030

Fax +4722453600

Email abdi@nakmi.no
Fragile states are characterized by violence directed toward civilians and social discord, which is often manipulated by power-seeking groups and organizations with conflicting interests. Thus, the absence of normal accountability is often the norm in fragile states. ${ }^{1}$ Somalia is ranked at the top of the list of fragile states, which is defined as a state that is "unable to perform basic functions such as maintaining security, enabling economic development, and ensuring the essential social and health needs of the popu- 
lation". ${ }^{2}$ Given the decades of armed conflicts, the country is not only in an ongoing political crisis, poor and corrupt, but it is incapable of accomplishing basic functions, including providing core services such as education and health to its citizens. The Somali government largely depends on aid, ${ }^{3}$ and despite billions of dollars of international aid dispensed, the vast majority of Somalia's largely impoverished population has had no option other than to use private health care services. ${ }^{4}$ Therefore, considering that the private health care system is the dominant health system in the country, ${ }^{5}$ exploring the accessibility to, as well as people's trust in, the private sector is essential to help to contribute to an equitable and affordable health care system in the country.

In 2005, the World Health Conference called for all nations to move toward universal health coverage, which is defined as "access to adequate health care for all at an affordable price". In conflict settings, local administrations often face significant challenges both in the provision of health services and in enabling access to services. Accordingly, $\sim 60 \%$ of maternal deaths, $53 \%$ of child deaths and $45 \%$ of newborn deaths occur in humanitarian settings. ${ }^{6}$ Conflict-affected countries often suffer severe disruptions to public health systems and when public health care fails, it leaves space for the private sector to fill in the gap. For example, the private sector provides $\sim 80 \%$ of all health care in Afghanistan. ${ }^{7}$ Nevertheless, researchers point out the risks associated with the private health sector in conflict settings. ${ }^{8}$ First, the private health sector may work for the selected wealthy few, leaving the poor majority out of affordable health care. ${ }^{4,5}$ Second, patients' lack of technical knowledge and the role of private providers in directing patient care may leave patients vulnerable to low-quality treatment, excessive use of diagnostics and overprescription. ${ }^{8}$

An equitable health care approach assumes that states are responsible for shaping and implementing the delivery of health care services to ensure equitable health access for all. In countries where public health programs have deteriorated, privatization has increased health care expenditures and failed to improve efficiency and equity. ${ }^{9}$ A study of privatization in some sub-Saharan countries in Africa showed that two in 10 persons used private providers, while five in 10 were priced out of access to health care. ${ }^{10}$ Another study reported that only $3 \%$ of the poorest fifth of the population was able to afford a private doctor when ill. ${ }^{9}$ Evidence shows that no low- or middle-income country in Asia or Africa has achieved universal or near-universal access to health care without relying solely or predominantly on tax-funded public delivery. ${ }^{11}$
Decades of armed conflict in Somalia have rendered the national public health care system dysfunctional; as a result, the health care system in the country has been virtually privatized. ${ }^{5}$ The delivery of health services is mainly carried out by private and nongovernmental organizations (NGOs), with limited government oversight in all regions. ${ }^{12}$ NGOs that work in the health care sector tend to focus on short-term needs and are reluctant to engage with the processes and institutions needed to build long-term sustainable solutions. There is a lack of studies that have investigated the private health system in Somalia, but some reports show that the private sector is unaffordable by a large segment of the population., ${ }^{4,5}$ This takes place in a context of widespread poverty in a country where two-thirds of the population live in severe poverty according to the United Nations Development Programme (UNDP). ${ }^{13}$ While available literature constantly stated lack of data on the private health system in Somalia, ${ }^{3,4,14}$ previous reports have stressed the need for research that explores people's trust in the private health system in Somalia. ${ }^{14}$ Therefore, the aim of this study was to explore users' trust in the public health system and the health care preferences of the people in Mogadishu, the capital city of Somalia.

\section{Methods}

\section{Study design}

A qualitative study using unstructured interviews was conducted in Mogadishu from August to November 2016. An unstructured interview is not only a flexible tool for assessing people's experiences and feelings of reality but also one that does not impose any a priori categorization that might limit the field of inquiry. Gaining trust and establishing good relationships are essential to the success of unstructured interviews, as only when a trustful and harmonious relationship is cultivated can the interviewee share his/her knowledge and experience on topics of interest to the interviewer.

A purposive sampling of 23 Somali participants was conducted in Mogadishu. We followed common research ethics principles in the carrying out of this study, including informed consent, in which the right to refuse, as well as withdrawal and confidentiality, was explained to each participant. Subsequently, verbal consent was obtained from the participants. The country has no ethical committee; however, the Ministry of Health (MOH) was informed about the study, and permission was obtained from them. The first author also evaluated whether there were any ethical dilemmas associated with the study, and no ethical challenges that require special attention were found. 
Among the study participants, seven were medical doctors who owned private health centers (Table 1), eight were patients, five were medical students and three were senior officials who worked for the $\mathrm{MOH}$. Participants were also interviewed in different settings.

The second and fourth authors, who are ethnically Somali, carried out the interviews. The interviewers developed trust and a close relationship with the participants prior to the initiation of the interviews. Moreover, participants were given information about the study's objectives, as well as the research question that the study intended to answer prior to the interviews. The interviews were conducted using the Somali language, which was the native language of both the participants and the interviewers.

\section{Consent for publication}

In this report, no details of the individuals, images, audio or video are included that require consent to publish.

\section{Ethical approval and consent to participate}

Study participation was voluntary, and information collected was strictly confidential. Participants were allowed to withdraw from the study at any time or decline to answer any question. Participants read an information sheet about the study, and after understanding the study objectives and procedure of the study, they gave informed consent either verbally or by signing the consent form. The study was approved by the Somali MOH.

\section{Content of the interview}

During the interviews, the terms xarumaha gaarka loo leeyahay (private facilities) and xarumaha dawladda (public facilities) were used, and the participants were asked about their understanding of these services, in addition to their perspectives regarding the services provided by the public and private institutions. We explored participants' trust toward the health care provided by the private health care sector. Lastly, the acceptable means of delivering equitable services to the community were explored, in addition to what they believe needed to be changed. The interview process continued until it was clear that no new information was emerging from the additional interviews, ie, when saturation was achieved.

\section{Availability of data and materials}

Data are stored in the first author's own computer and are only available to the authors.

\section{Analysis}

The first author transcribed the interviews verbatim, and the transcripts were thoroughly read several times by the first, third and fourth authors. A thematic analysis was used to identify and analyze important themes ${ }^{15}$ with the coding process involving recognizing and encoding the identified themes prior to interpretation. According to Leininger, ${ }^{16}$ themes can be identified by bringing together fragments of ideas, experiences and beliefs that are often meaningless when viewed alone. For that reason, themes that emerged from the informants' stories were pieced together to form a comprehensive picture of the participants' shared experiences. The themes that were identified through coding were divided into categories based on the participants' experience in private health care. Seven main categories emerged after the careful analysis of the data, and they are presented in the "Results" section. We interviewed people from different walks of life, including policymakers and private health care owners, as well as patients and members of the public, and the consistency of the findings from different interviews has served to ensure the trustworthiness and credibility of the results. Furthermore, two medical doctors with several years of working experience in Mogadishu and two ordinary citizens who live in Mogadishu have read the final manuscript, and they have verified that the existing situation in Mogadishu is presented correctly in the paper.

Table I Characteristics of private health centers owned by the doctors involved in this study

\begin{tabular}{|c|c|c|c|c|c|c|}
\hline Health facilities & Date established & Number of staff, $n$ & Number of doctors, $n$ & $\begin{array}{l}\text { Estimated number of } \\
\text { outpatients per day, } n\end{array}$ & Visit fee, $\$^{a}$ & Ownership \\
\hline I & 2015 & 9 & 1 & $20-25$ & 3 & Private \\
\hline 2 & 2008 & 4 & I & 20 & 10 & Private \\
\hline 3 & 2013 & 12 & 3 & $26-30$ & 6 & Private \\
\hline 4 & 2010 & 14 & 2 & $30-40$ & 10 & Private \\
\hline 5 & 2007 & 17 & 4 & $15-30$ & 5 & Private \\
\hline 6 & 2010 & 14 & 3 & $25-35$ & 10 & Private \\
\hline 7 & 2008 & 20 & 1 & $15-25$ & 10 & Private \\
\hline
\end{tabular}

Note: aMean fee: US\$8. 


\section{Results}

\section{The reason for the privatization of the country's health care system}

The study participants consistently agreed that the country's health care is overwhelmingly provided by private providers.

According to several respondents, the private health care system has filled the vacuum generated by the absence of the public health care system. Most of the participants think that, despite the low quality, people in Somalia would not have accessed health care at all and the situation would have been much worse without the private system.

The vast majority of Somalia's health care is provided by private providers. Because of the absence of the Ministry of Health's role, the private providers took over the health care provision in the country. After the collapse of the Somali government and its health services in 1991, individual citizens came up with an initiative to do what they could to fill the gap. As a result, there were business community and medical doctors who decided to establish private health facilities to provide health care to the people. This initiative has been introduced to all regions in the country and those who afford it got access to private health care. [Participant 1]

They sustained the provision of health care in the absence of government, but they have their weaknesses too. Regardless, people who afford it can obtain health care from the private facilities whenever they need care. [Participant 5]

One of the study participants attributed the privatization of the health care sector to the private education system in the country. He mentioned that almost all universities in the country are private universities that charge lots of money from medical students. Therefore, when medical students graduate, they want to repay the fees to their families, who have paid for their school fees. Hence, the only option they have for paying their families is to have private clinics.

The private health care owners are those who graduated from private universities. They were paying high school fees. When they are learning, they only think about money with the belief that having a private clinic in the future can make them super rich. When they graduate, they rush to establish private clinics with a strong desire to make money. [Participant 2]

\section{The private health care sector is unregulated}

Several participants, including officials from the $\mathrm{MOH}$ and medical students, agreed that the private health care provid- ers are free to do whatever they want, with no authority that inspects and regulates their services to make sure that they meet the fundamental standards of quality. Participants repeatedly mentioned the overprescription of drugs just to sell out the drugs in the doctor's pharmacy. It was also mentioned that a doctor might prescribe the same drug to several patients with different health conditions just because this particular drug is largely in stock and needs to be sold out. All these behaviors were associated with lawlessness in the country and the government's inability to control and regulate the private health care system. Here are some of the quotes from various participants:

Somalia doesn't have a government that regulates health services. People are free to establish their private facilities, and nobody knows who is qualified to do so and who does not. Service providers are free to treat the people in the way they want without fear of any legal consequences. They are only concerned about the number of people coming to their facility and the amount of money they earned from their patients that day. [Participant 6]

The government does not regulate the drugs, and therefore the drugs are of low quality and very expensive, particularly when they realize that this particular treatment is not available in other health facilities, so they sell it for even higher prices. [Participant 6]

There is no government that can regulate the private health system. There are pharmacies everywhere that sell not only pharmaceuticals but also kerosene, sugar, oil and food together at the same store, which is wrong. These are people with no health background who run health facilities, and they provide all types of health services. The absence of government regulations has created lots of problems. [Participant 1]

There are no regulations agreed on by the $\mathrm{MOH}$ and private health providers. But there is a medical service unit in the $\mathrm{MOH}$, and they are in the process of drafting guidelines for private health providers. However, the $\mathrm{MOH}$ doesn't have the capacity to control the health system in the country. We are trying to develop guidelines that help the private health system and the $\mathrm{MOH}$ to cooperate and work together for the safety of the people. [Participant 13]

The $\mathrm{MOH}$ has developed regulations for private health providers, but these regulations are not enforced and not implemented. [Participant 14]

\section{People's experience in the private health care system}

In the absence of government regulations and jurisdictions that protect patient's rights, the private system is reported to 
go as far as they can to make money through unethical means. The issues raised by participants included lack of respect for patients and a lack of patient-doctor relationships. The patients described their interaction with doctors as solely a business one. Participants mentioned that the doctor who attended to the patients owned the laboratory and pharmacy too. Therefore, the overprescription of laboratory tests and drugs is widely reported, whereby patients undergo a number of laboratory checkups in each visit and buy drugs that are not required. Moreover, some of the participants stated that it is common in Somalia for pharmacies to sell expired drugs, while food stores sell expired food items with no fear of any legal consequence at all.

Private clinics are owned by individuals who pursue their own financial interest. To receive more profit, they often send patients to a number of laboratory checkups. They also prescribe plenty of drugs, which you should buy from their own pharmacies. As a patient, you may not even have a clue about the prescriptions you are given. Those kinds of behaviors negatively affect patient's trust toward private facility owners. [Participant 5]

People do not receive appropriate health care...the doctor is on a moneymaking mission and they don't care about the patient's needs. They give you prescriptions, sometimes a full plastic bag of different drugs. The treatment is very expensive, yet they give you a prescription that they know you cannot find at any other pharmacy except their own pharmacy. Patients have no other option than to buy the treatment regardless of the cost. Doctors don't care about your situation, they only care about money. [Participant 3]

Sometimes they prescribe an expired drug, they don't care. If you ask for explanations about the prescription, they just say "you are a patient, take the prescriptions and stop talking." They only think about money and about the number of patients they attended to that day. There is a business competition among doctors and every doctor thinks about the profit of the day and how many houses one can buy in the town. [Participant 2]

\section{Trust toward the private health care system}

Participants expressed their distrust toward the private health care system, despite the limited options available to them. Among the reasons proposed were lack of respect to patients, lack of empathy to patients from poor families and poorquality services, which - according to one participant - has a strong potential to discourage people from seeking care when they become sick.

In the hospital, you expect to be asked about your situation first and then the money. In this approach you feel you are respected, you feel that the health care provider is concerned about your health and you feel relieved. But if you are asked about money first, and the reason for coming afterward, you feel disrespected and that is how it works in private hospitals here. In fact, when I fall ill and my parents want me to go to a hospital, I often refuse it, because I know they don't have any respect for patients. [Participant 2]

Respect is an important issue in life. We need to be respected as equally as we need food. If you feel disrespected, you feel miserable about your life. The staff of the private hospitals here don't respect patients. When you arrive at the health facility, they don't even give you a place to sit. When you are buying the number (ticket) to the doctor, you get an impression that you are dealing with a shopkeeper. You don't feel any patient-doctor relationship or connection. After you pay the visiting fee, you are no longer treated as a patient, but as an ordinary visitor, and nobody cares about your presence. [Participant 2]

\section{Preference of public health services for quality and equitable health care}

Given the inequality in health care and the low-quality services provided by the private health care sector, the majority of the study participants, including doctors who own private facilities, agreed that public health care services owned by the government should provide affordable and equitable health care to the general population, the majority of which is poor. Some of the participants also mentioned that people die of preventable conditions because they are not able to pay the health care fees, and they may even opt not to seek health care services. Below are some of the quotes from participants:

I would be happy to see public hospitals where the government controls the quality and pay the salary for the doctors. The public system would provide services to all people regardless of their financial capabilities. The poor people who are able to use the private system are more than those who are enabled to use private health care. The poor people cannot use private services because they don't have money. If they pay the visiting fee, they cannot buy the treatment or laboratory tests. The public health care system is important for poor people. [Participant 5] 
We need a health system that promotes equal treatment for people who have money and those who don't have money. If there were public hospitals, many poor people who are suffering from illness or who are dying of treatable diseases would have received care. There are people dying of diarrhea but they don't have money to go to a hospital. Also, the private facilities are open only when the owner wants it to be open, but the public hospitals would provide 24 hour services. [Participant 3]

Public hospitals that are owned by the government would help the poor people because they would receive health care just like the rich people. The public hospitals would provide services that the private hospitals don't provide, such as good hospitality. The rich and poor would receive equal treatment and seek care at the same place, and people would also receive good prescriptions and quality drugs. [Participant 1]

\section{Obstacles to the public health care system}

Almost all the medical doctors interviewed agreed that there is no functional government with the capability to provide public health care services to the people. Therefore, they think that government-related factors serve as barriers to an effective public health care system in the country. The factors mentioned include poverty, as well as the government's lack of competence and commitment to provide public services to its citizens.

There are many problems that are hindering the public health system, which include the government's inability to pay the salary of the health staff, provide drugs and other necessary facilities. [Participant 7]

Barriers are many. For example, the country has no money to invest in public services; second, there is no functional government that controls the country. [Participant 10]

\section{Factors that may improve the private health system}

The study participants expressed their perspectives on what has to be changed and how the health care services in the country should be improved. They presented different suggestions, ranging from quality education for medical students to a competent government that regulates the private health care system, improves public health care services and comes up with strategies that promote equitable and affordable health care in the country.
I would suggest that private hospitals should reduce the user fees to a level that poor people can afford when they become sick. On the other hand, there must be strict control of drugs that doctors prescribe to patients. Sometimes, they give patients a drug that has nothing to do with the patient's condition and patients spend lots of money for buying that drug. This drug may cause more harm to patients than good. [Participant 5]

I would suggest that doctors should think about the quality of the care and to think about their moral duties as a doctor, and not only money. If they save a patient, he/she will go back to work and contribute to the economy of the country. [Participant 3]

The source of incompetence in the health sector is a poor education system in the universities. I think that is where it all begins. If things are corrected from the base, that is all, everything will be fine if education system is improved. [Participant 1]

Medical students should be taught about ethics and their responsibilities, which is not to make money but to save people. [Participant 2]

\section{Discussion}

This study explored the trust toward the private health care system and its accessibility in Mogadishu, Somalia, a topic that has not previously been documented in the literature. The results show that the vast majority of Mogadishu's health care is provided by the private sector, which has stepped into the vacuum left by the government due to its inability to run social services such as health care, and these private facilities are often the only point of contact for patients seeking health care in Mogadishu. In line with prior reports, our findings show that the growth of the private system is encouraged by a lack of commitment and financial capability by the Somali government to support a public health care service. ${ }^{4,5,17}$ Consequently, the private system and community self-financing mechanisms are considered the only option for sustaining health care services. An earlier report shows that only $20 \%$ of Somalia's population has access to any health care and that two-thirds of them use a private health care system that is predominantly run by individuals and groups who pursue profits with no incentive to serve those unable to pay. ${ }^{4,17}$ According to our findings, access to health care services in Mogadishu is based on the ability to pay rather than need. Therefore, the rhetoric of many organizations and political actors about successes in the health sector field in Somalia diverges significantly from the reality on the ground. 
In agreement with prior reports, ${ }^{3,5,17}$ our findings show that the private health care system in Somalia is not only unregulated but also very costly in that most of the families cannot afford to pay for their sick family members. An earlier report stated that the cost of health care in private facilities in Somalia is often unaffordable by poor families, ${ }^{17}$ According to the $\mathrm{MOH}$, high fees are charged for the use of any aspect of health care services, including registration fees, consultation fees, fees for drugs and fees for medical supplies, hence resulting in a great disparity in access to health care between the poor and the rich patients. ${ }^{5}$ Study participants reported prescriptions for inappropriate treatments, a tendency to conduct unnecessary laboratory tests, the excessive use of higher diagnostic technologies and overcharging, including the widespread practice of further appointments for follow-up, all of which inflate the cost. Literature shows that the overprescription of drugs to maximize the profit and the dispensing of expired drugs by inadequately trained staff can lead to misdiagnosis and drug resistance, particularly anti-tuberculosis (TB) drugs, antimalarial drugs or antibiotics. ${ }^{4}$ Ample evidence shows that when costs are increased, the poor are more likely than the nonpoor are to be averse to the utilization of health care services. ${ }^{18}$ This study shows that the mean visiting fee is US\$8 in small clinics, whereas the cost may inflate when laboratory tests and drugs are included. This exists in a setup in which the majority of the population utilizes the services of the private health sector but has no control over the treatment provided and the quality of care. This finding is consistent with a recent review by the United Nations Children's Fund (UNICEF), which stated that cost is a barrier to seeking health care, including the cost of transportation, consultation and the visiting fee. ${ }^{19}$ Another study in the northern regions of Somalia also stated that the cost of treatment is the biggest hurdle for those seeking any health care at all. ${ }^{20}$

Our result highlights that the Somali people, despite not having many options, have no trust in their private health care system. This was attributed to both a lack of respect to patients by private health care providers and their prioritization of money over the quality of care. Trust is defined as "the optimistic acceptance of a vulnerable situation in which the trustor believes the trustee will care for the trustor's interests". ${ }^{21}$ The people's trust toward the system is dependent on the quality of care, as the provision for a good quality of care can build trust, and better trust may, in turn, improve the quality of care. Moreover, trust plays an important role in health care, as it underpins the cooperation between the doctor and the patient. The doctors know more about the treatment options and the cost of the treatment, whereas patients know about their health problems and financial capabilities. ${ }^{22}$ Our findings of the patient-provider interaction reflect the paternalism model well. ${ }^{8}$ Medical paternalism is a set of attitudes and practices in medicine in which a physician determines how a patient is treated while the patient's wishes and choices are not honored. According to the paternalism model, the paternalist physicians treat their patients as illnesses, not as persons, and they do not take into account a patient's value system, which includes a broad range of considerations beyond illness that might affect decision-making. ${ }^{8}$ Studies suggest that quality patient-provider interaction is a critical element of health care services, while patient satisfaction is an outcome measure. ${ }^{23}$

A widely shared grievance among the study participants was the lack of transparency about the nature, quality and appropriateness of the treatment provided. Consequently, the study shows that patients either stop seeking care or approach private services with apprehension, fearing poorquality treatment and a high cost of the visit, while private providers do not seem to feel they are accountable to the public. This finding is in accordance with a previous report stating that the lack of regulation and inspection in the private sector in Somalia, coupled with the large number of unqualified private sector providers, may lead to many people receiving wrong - or even dangerous - treatments from unregulated, low-quality private sector providers. ${ }^{4} \mathrm{~A}$ prior WHO report stated that the private health care sector in Somalia is unregulated and, as such, "can be a risk rather than a solution to health problems", particularly in the context of the widespread import of cheap uncertified drugs and selfmedication, which risks developing a drug resistance that constitutes a health threat for Somalia and the entire region. ${ }^{4}$ However, the medical profession obliges doctors, nurses and midwives to always act with their patients' welfare in mind above everything else, including their own interests. It is imperative to mention that the participants highlighted that the unethical behavior of some doctors in Somalia is influenced by the privatization of medical schools, which costs them a lot of money. Clearly, when medical students invest a huge amount of money in a medical school, their need to recoup their school fees will surely compete with the responsibility to do the best for their patients. Improving the quality of education in medical schools, particularly strengthening the medical ethics field, is imperative in doctors' understanding of the obligations involved in the medical profession. 
This study shows that participants would prefer the public health care system, which they think would be more friendly and would provide quality care, in addition to the provision of an equitable care based on need rather than on the ability to pay. Their preferences for the public health system, however, lack comparison, as the public health system is currently almost nonexistent in Mogadishu. The reason for preferring the public health system could be the view that the public health system would operate under the government guidelines and thus would prioritize patients' safety and rights. It is worth noting that the Somali government banned private medical practices in 1972 and obliged all physicians in the country to devote all their time and energy to serving their needy people and not to run after personal gains. ${ }^{3}$ Although the ban on private practice of health care was lifted in the late 1980s, it has become the dominant health provider after the collapse of the Somali State in 1991. Therefore, participants' preference for the public health system could be because it was the only health care system that people were familiar with before the civil war. Almost all the participants attributed the absence of the public health care system in the country to poverty and the financial inability of the government. Our finding is consistent with a previous study in Cambodia, where people trusted public health care providers for curing their conditions and providing friendly care. ${ }^{22}$ Although the participants of our study repeatedly noted poverty as a barrier to building a national public health system, poverty cannot justify the government's neglect of the public health care services because public health care itself is understood to be a basic service essential in any fight against poverty. Furthermore, some very poor countries have successfully built some of the best public health care systems in the world. For example, a Sri Lankan woman can expect to live almost as long as a German woman, despite an income that is 10 times smaller. Similarly, a Sri Lankan woman has a $96 \%$ chance of being attended to by a skilled health worker when giving birth. This was attributed to a quality public health care system and universal access to affordable and equitable health care. Making Somalia's public health care system work takes political commitment and leadership, as well as investments and good policies.

This study has its limitations. First, the reported result contains the perspectives of 23 participants, but different channels of information presented similar views; hence, it may be a view shared by many people in the country. Second, the study is an exploratory study with a limited sample, and therefore, it cannot be generalized. Despite the limitations, this study highlights the shortcomings of the expensive, unregulated and unplanned private health care sector in Mogadishu, as well as the frustration of the users toward the private health providers' code of conduct.

\section{Conclusion}

The study findings underline the need for the Somali government to develop regulatory mechanisms and guidelines with the potential to guide the private health care system to provide equitable and affordable health care. The study shows poor patient-provider relationship, which demands guidelines for the private health sector to provide dignified care to patients. The education system, particularly the syllabus used by medical faculties, should be reviewed and improved to provide medical students with necessary knowledge, skills and attitudes to maintain professional rapport with patients, uphold patients' dignity and respect their rights. In the long run, a tax-funded public health care system, in partnership with a government-subsidized private health care system, should be the target for the government to achieve a universal coverage of equitable health care in the country.

\section{Acknowledgments}

The authors wish to thank the Somali Ministry of Health for collaborating with the study team. Moreover, the authors also thank the participants of the study for their participation and help. The study was not financially supported by any institution or individual.

\section{Disclosure}

The authors report no conflicts of interest in this work.

\section{References}

1. Hallam A. Evaluating Humanitarian Assistance Programs in Complex Emergencies. 1998. Available from: http://www.livestock-emergency. net/userfiles/file/common-standards/Hallam-1998.pdf. Accessed February $19,2017$.

2. Haar RJ, Rubenstein LS. Health in Postconflict and Fragile States. United States Institute of Peace; 2012; Washington DC.

3. World Health Organization (WHO). Health System Profile Somalia. Geneva: World Health Organization; 2006.

4. World Health Organization. Regional Health Systems Observatory (EMRO). Health Systems Profile - Somalia. WHO, Geneva, 2006.

5. Ministry of Health, Somalia. Health Sector Strategic Plan January 2013. 2016. Available from: http://www.nationalplanningcycles.org/ sites/default/files/country_docs/Somalia/the_federal_government_of somali_republic_health_sector_strategic_plan_2013-2016.pdf. Accessed February 19, 2017.

6. Temmerman M, Khosla R, Bhutta ZA, Bustreo F. Towards a new global strategy for women's, Children's and Adolescents' Health. BMJ. 2015;351:h4414.

7. Hanson K, Gilson L, Goodman C, et al. Is private health care the answer to the health problems of the world's poor? PLoS Med. 2008;5(11):e233. 
8. Emanuel EJ, Emanuel LL. Four models of the physician-patient relationship. JAMA. 1992;267:2221-2226.

9. Rowden R. The Deadly Ideas of Neoliberalism. London, New York: Zed Books; 2009.

10. Buchs TD. Privatization in Sub-Saharan Africa: Some Lessons from Experiences to Date. 2003. Available from: www.nioclibrary.ir/privatization/e025.pdf. Accessed February 07, 2017.

11. Commission on the Social Determinants of Health. Closing the Gap in a Generation: Health Equity through Action on the Social Determinants of Health. Geneva: World Health Organization; 2008:100.

12. UNICEF, Somalia [webpage on the Internet]. Priority Issues. 2016. Available from: http://www.unicef.org/somalia/health_53.html. Accessed February 09, 2017.

13. United Nations Development Program. Human Development Report 2015. 2016. Available from: http://hdr.undp.org/sites/all/themes/ hdr_theme/country-notes/SOM.pdf. Accessed December 15, 2016.

14. UKaid. Assessment of the Private Health Sector in Somaliland, Puntland and South Central. 2015. Available from: http://charliegoldsmithassociates.co.uk/wp-content/uploads/2016/05/Assessment-of-thePrivate-Health-Sector-in-Somaliland-Puntland-and-South-Central.pdf. Accessed February 07, 2017.

15. Taylor S, Bogdan R. Introduction to Qualitative Research Methods: The Search for Meanings. New York, NY: John Wiley and Sons; 1984

16. Leininger M. Ethnography and ethnonursing: models and modes of qualitative data analysis. In: Leininger M, editor. Qualitative Research Methods in Nursing. New York, NY: Grune and Stratton; 1985:33.
17. Jeene H. The Health System in Karkaar Region, Puntland, Somalia. 2010. Available from: http://www.academia.edu/2955558/Analysis_of_ the_Health_System_in_Karkaar_Region_Somalia. Accessed March 23, 2017.

18. Gertler P, van der Gaag J. The Willingness to Pay for Medical Care: Evidence from Two Developing Countries. Baltimore, MD: John Hopkins University Press; 1990.

19. Mazzilli C, Davis A. Health Care Seeking Behavior in Somalia. A Literature Review. UNICEF; 2009. Available from: https://www.unicef. org/somalia/SOM_HealthcareseekingbehaviourReport_10-WEB.pdf. Accessed March 29, 2017.

20. Save the Children (UK). Health Baseline Survey for Togdheer Region, Somaliland. Draft Report. 2008.

21. Hall MA, Dugan E, Zheng B, Mishra AK. Trust in physicians and medical institutions: what is it, can it be measured, and does it matter? Milbank Q. 2001;79(4):613-639, v.

22. Ozawa S, Walker DG. Comparison of trust in public vs private health care providers in rural Cambodia. Health Policy Plan. 2011;26(suppl 1): $\mathrm{i} 20-\mathrm{i} 29$.

23. Oetzel J, Wilcox B, Avila M, Hill R, Archiopoli A, Ginossar T. Patientprovider interaction, patient satisfaction, and health outcomes: testing explanatory models for people living with HIV/AIDS. AIDS Care. 2015;27(8):972-978.
Risk Management and Healthcare Policy

\section{Publish your work in this journal}

Risk Management and Healthcare Policy is an international, peer-reviewed open access journal focusing on all aspects of public health, policy, and preventative measures to promote good health and improve morbidity and mortality in the population. The journal welcomes submitted papers covering original research, basic science, clinical and epidemiological

\section{Dovepress}

studies, reviews and evaluations, guidelines, expert opinion and commentary, case reports and extended reports. The manuscript management system is completely online and includes a very quick and fair peerreview system, which is all easy to use. Visit http://www.dovepress.com/ testimonials.php to read real quotes from published authors.

Submit your manuscript here: https://www.dovepress.com/risk-management-and-healthcare-policy-journal 